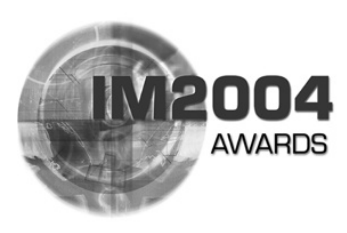

\title{
THE 2004 INFORMATION MANAGEMENT AWARDS
}

The Information Management Awards are the premier European recognition of excellence and innovation in the management of business information. They are a showcase for organisations that have demonstrated the vision and business skills to implement very successful projects based on leading-edge technologies such as CRM, business intelligence, supply chain and content management.

The presentations took place at the IM2004 Awards dinner at the Grosvenor House Hotel on Thursday 2nd December in front of an audience of nearly 1050 finalists, press and guests. The host and entertainer for the evening was Barry Cryer, veteran of countless radio and television comedy shows.

From 19 original entries in the Business Intelligence Project category, Broadland Housing won the Award for their project RSL Manager, partnered by Reidmark. The Award was presented by Alan Parker, Sales \& Marketing Director of Temtec Europe, the sponsors of the Business Intelligence Award. Broadland Housing were also commended in the Premier Project Award for the best overall project.

The exclusive media partner for the Business Intelligence Award was the Journal of Database Marketing \& Customer Strategy Management and John Ozimek, Managing Editor of the journal, was on the expert judging panel. The Business Intelligence Award was sponsored by Temtec Europe. The full list of winners and synopses of the winning entries can be found at http://im2004.elanconf.co.uk/winners.php.

This is a case study of the work carried out by Broadland Housing. It contains a description of the project and its aims, the business rationale and the business benefits realised.

\section{PROJECT OVERVIEW}

RSL Manager is the first e-business management and CRM system for the social housing sector. It was developed by Broadland Housing, a housing association, in partnership with Reidmark, an e-business software development company.

RSL Manager drives business critical information at the right time to the right people, all within a monitored environment. As well as dealing with all traditional housing management functions like rent accounting and repairs, its functionality has been embedded around customer relationship management (CRM).

This means that there is a single chain of information and actions that emanates from the initial contact with the customer and that is contained within a single 'hosted' business system environment.

The resulting harmonisation is already proven to make outstanding improvements in operational efficiency and cost control. RSL Manager provides Broadland Housing with an e-business opportunity to join up the processes, 
procedures and relationships between the organisation, its customers, its staff, its suppliers and its partners.

\section{THE BUSINESS OBJECTIVES}

The purpose of the project was to develop a new organisational system for social housing businesses based on managing customers that would ultimately drive up the service standards within the sector.

Social or affordable housing has gained an unfair reputation based on the perception that it is low quality and located in poor areas and therefore considered to be the housing of last resort. In September 2003, the National Housing Federation (NHF) launched 'iN Business for Neighbourhoods'. The overriding aim of this action for change was to make housing associations more effective individually and collectively, through renewed commitments to neighbourhoods, customers and excellence.

Existing housing systems are based around managing the 'property' and not the customer. This has led to department-based information management where customer management and decision making is hindered by poor access to business critical data. In some instances customer information is limited to name, address and rent history.

Following a market review, Reidmark concluded that the housing sector needed a fresh approach to organisational systems that would enable associations to respond to the aspirations of the NHF iN Business objectives. The principal aim is to support the entire business through a system that is customer focused, business efficient and able to manage neighbourhoods dynamically. This meant implementing a business system that empowered everybody in the organisation, including the Chief Executive, to deal with a customer at any time and from any location.
In November 2003, Reidmark and Broadland Housing joined forces to develop RSL Manager - the first e-business system for the sector. The partnership was formed to provide Broadland Housing with a new organisational system that would bring together customers, neighbourhoods, property management, finances and employees in one single system.

The objectives were as follows:

- introduce a CRM culture, fully supported by a customer orientated system

- harmonise the organisation through a single system environment

- increase the ability to hold and share personal knowledge

- increase access to business critical information

- develop cohesive supply chain management with contractors

- improve efficiency across the organisation

- decrease fragmentation of processes and data

- maximise the benefits of an e-business environment

Through the implementation of these objectives, RSL Manager supports the business in four key areas:

- A commitment to building customer relationships so that the customer can be managed from the point where they first express an interest in a service or a need.

- A real-time working solution that can be accessed by customers and suppliers through a 24/7 hosted application.

- The capability to work with communities to efficiently deal with all neighbourhood issues in a technology-enabled partnership with other agencies.

- The development and dissemination of the business strategy that is seamlessly 
linked to the monitoring of performance for more effective day-to-day management.

RSL Manager has been specifically designed to support the efficient management of the key functions associated with managing tenants in properties, but also the ability to manage the business strategically.

It was essential that the project was not seen as an IT program, and therefore, emphasis was placed on involving people who had day-to-day contact with customers and who were very familiar with the issues that the organisation faced on a daily basis.

One of the biggest challenges facing a housing association is managing the financial aspects of the business, which includes rent collection through a variety of sources. This part of the CRM is essential in demonstrating a customer orientation. People involved with any aspect of the financial chain were, therefore, involved in the project team.

\section{TECHNOLOGY INFRASTRUCTURE}

RSL Manager has been developed using internet technology so that housing associations can adopt a cost effective approach to their system requirements. As a hosted application, RSL Manager offers a solution to all organisations irrespective of their size and IT department infrastructure.

The software is based on a client/service architecture using a Microsoft platform. All programming is carried out using ASP, Javascript, Vbscript and SQL. Reidmark develops the user interface and bespoke software/coding for all operational business processes.

The system is hosted in secure environments with third party server providers - this includes system redundancy, data back up and downtime protection. Through the hosted application route it has been possible to significantly cut networking expenditure, particularly where numerous sites are involved. This project had to bring together four separate sites that can now access information in a real-time environment, thereby offering the most up-to-date picture possible. This has been essential in dealing with customer financial transactions which take place in local offices and which need to be managed by the central finance team.

\section{IMPLEMENTATION}

Reidmark had constructed a prototype of the system to provide an indication of the approach that could be taken. This approach fitted with Broadland Housing's visions for their systems and it agreed to develop the prototype further through the project. This required detailed examination of existing processes and procedures. Following a six week review, recommendations were made on how Broadland needed to change existing approaches to develop a better customer orientation. This included reviewing working practices across the organisation so that the integration offered by RSL Manager could be maximised.

The project consisted of two distinct phases. During November and December 2003, phase one concentrated on evaluating existing processes and the realignment of customer services. This included a full evaluation of the role of the system and driving up the understanding within the business of how each department had a role to play in a customer-orientated business environment. From January through to March 2004, phase two embraced the development of the system and the implementation of detailed process specifications.

The system's live date was set at the 


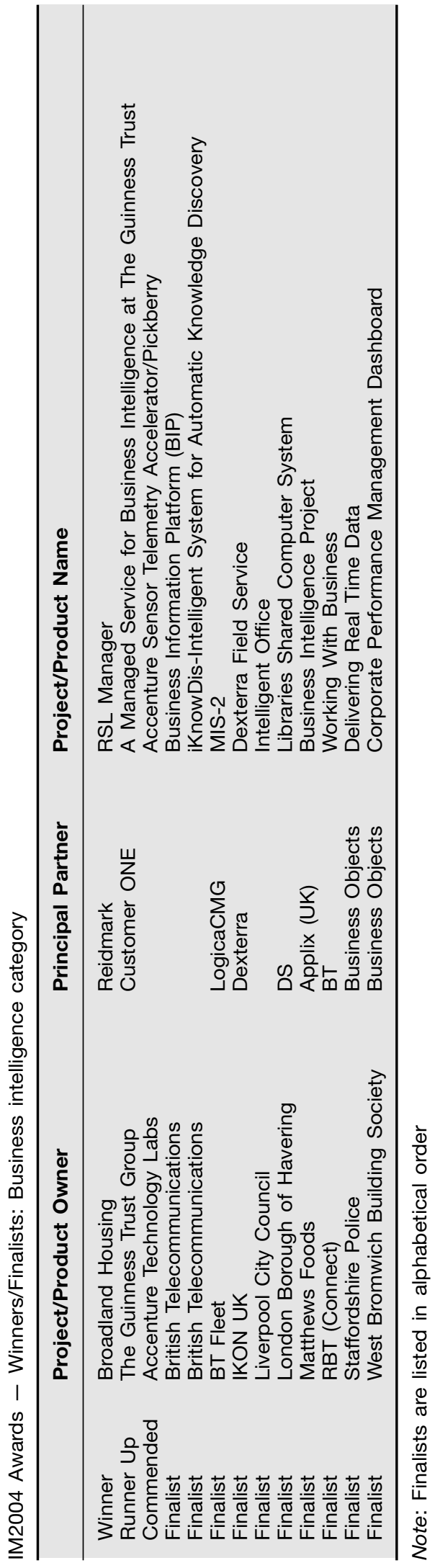


beginning of the current accounting year (5th April, 2004). The priority was to ensure that all front line customer services were in place to guarantee that there was zero disruption.

During the period January-April 2004 the CRM tools were built together with related financial and supplier processes in the following areas:

- rent accounting

- repair management

- supply chain management

- integration with e-banking

- employee relationship management

- tenancy management

- expenditure commitment and purchase ordering

- property management

- budget management

In addition, data from legacy systems covering 4,000 properties and over 5,000 customers were reviewed and re-engineered to allow the data to be incorporated into a CRM framework.

During April-September 2004, the system was reviewed and modifications made to phase one processes. Further developments were also introduced in the following areas:

- automated rent arrears management

- management information tools and reporting

- performance monitoring

- development budget planning and expenditure

- bankers' automated clearing system (BACS) payments, standing orders and direct debits

- housing benefit calculators and payments

- multiple repairs ordering

- part reconciliation of invoices

Improved financial control coupled with a tougher inspection regime, focused on the ability of housing associations to deliver best-value services, which meant financial management was always a goal within the project. The approach taken to deliver this goal changed, however.

During the implementation programme it was agreed that further financial processes would be included within RSL Manager, which included development of a 'nominal ledger' function so that all accountancy can take place within RSL Manager. This included:

- journal entries

- expenditure reconciliation

- BACS payments to suppliers

- direct debit payments

- customer payment cards (linked to post offices)

- income payments through standing orders, direct debits and housing benefit

- cost centre reporting

- income reports

- VAT management and payments

- expenditure reports

- management accounts

This required a major rewrite of the financial processes to ensure that RSL Manager was able to respond to the statutory financial requirements of a housing association. The financial performance of the business is closely aligned with the efficiency in rent collection. As part of the proposed changes, enhancements were made to the way in which Broadland Housing could manage the collection and arrears process. In keeping with the CRM philosophy, RSL Manager increased its ability to support this area of the business through the sharing of relevant financial information that had previously been held within the finance department. This included real time rent statements that presented the front line customer service 
team with a rent account that reflected up-to-the-minute financial data. This included an integrated housing benefit estimator to ensure that arrears processes were carried out in line with a customer's financial arrangements.

\section{ENHANCED LEVELS OF CUSTOMER SERVICE}

In the past it had not been possible to record and share information about a customer relationship throughout the organisation. The introduction of RSL Manager has enabled Broadland Housing to manage all aspects of the customer relationships.

The structured recording of client interactions has helped staff to manage individual customer relationships and provide quality information for customers. This has encouraged all employees to feel that they can help a customer as they have access to the same information. Dealing with a knowledgeable and helpful person is essential to good customer service. RSL Manager has enabled this to be a reality for Broadland Housing through the dynamic sharing of information and data across all management and service delivery teams.

Broadland Housing have seen real improvement in the application of customer related financial information, which can now be viewed by front-line staff and customers in a real-time environment. Previously this information was available on request from the finance team and was not presented as part of an overall customer account with all other related information. Simple requests like sending a rent statement or setting up direct debits now take place within seconds. More complex procedures all take place in a real-time system environment, for example rent payment information is placed onto the customer account instantaneously.

\section{DELIVERY OF BUSINESS BENEFITS}

The management at Broadland Housing need to respond to a challenging agenda of change. The project has provided them with confidence in responding to issues such as:

- A tighter financial situation, where returns on investment and the efficient use of resources are paramount.

- Customers who are more discerning and have a negative perception of social housing and the organisations working in it.

- A tougher inspection regime focusing on the ability of housing associations to deliver best value services.

- A desire on the part of government for housing associations to play a bigger role in the management of neighbourhoods and work in partnership with others to do so.

The integration of all areas of the business within a single system significantly reduces duplication of data and, therefore, errors. The result is high-quality reports from data that are truly representative of the business. The management team and the Board can generate management information (MI) at the click of a mouse on the 'health' of the business and demonstrate areas of improvement, effectiveness, financial integrity and quality.

More information can be found at: www.broadlandhousing.org;

www.reidmark.com; im2004.elanconf.co.uk.

For more information on the Information Management Awards, please contact Lisa Di Bernardo, Elan Conferences Ltd, tel: +44 (0)1707 373701; e-mail: lisad@elanconf.co.uk 